\title{
Práticas educativas parentais em relação ao filho único e ao primogênito'
}

\author{
Parental child-rearing practices in respect \\ of only children and first born
}

\author{
Ana Paula Corrêa de Oliveira FREITAS ${ }^{2}$ \\ Cesar Augusto PICCININI²
}

\begin{abstract}
Resumo
O objetivo deste estudo foi examinar eventuais diferenças das práticas educativas parentais em relação a filhos únicos e primogênitos de famílias com dois filhos. Participaram 12 famílias com filho único e 10 com dois filhos, emparelhadas conforme o nível socioeconômico, idade e gênero das crianças. A idade dos filhos únicos variou entre 4,6 e 6,1 anos ( $M=5,5, D P=0,51)$ e a dos primogênitos entre 4,3 e 6,3 anos $(M=5,1, D P=0,78)$. Mães e pais dos dois grupos responderam a uma entrevista sobre práticas educativas parentais, cujas respostas foram submetidas à análise de conteúdo. O teste do qui-quadrado revelou diferença marginalmente significativa somente nas práticas maternas e paternas em relação ao filho único. Verificou-se semeIhança nas práticas educativas entre mães e pais em ambos os grupos. Os resultados foram discutidos à luz da literatura, buscando entender os fatores que podem contribuir para explicar semelhanças das práticas educativas utilizadas para filhos únicos e primogênitos.
\end{abstract}

Unitermos: Atitudes parentais. Educação infantil. Filhos únicos.

\begin{abstract}
The aim of this study was to examine potential differences in parental child-rearing practices in respect of only children and first born of families with two children. Twenty-two families participated in this study, 12 with only children and 10 families with two children. Families were matched according to socioeconomic level, age and the children's sex. The age of the only children ranged from 4.6 to 6.1 years $(M=5.5, S D=0.51)$ and the first born were aged from 4.3 to 6.3 years $(M=5.1, S D=0.78)$. Mothers and fathers in both groups were interviewed about parental child-rearing practices and their responses were content-analyzed. The hypothesis of the study was not supported. According to the chi-square test, only marginally significant differences were obtained in maternal and paternal child-rearing practices in respect of the only child. Results indicated agreement between the mothers' and the fathers' child-rearing practices in both groups. Issues described as determinants of childrearing practices are discussed, taking into consideration the role of the family in child development.
\end{abstract}

Uniterms: Parental attitudes. Child rearing. Only children.

UVV

1 Artigo elaborado a partir da dissertação A.P.C.O. FREITAS, intitulada "Práticas educativas parentais em relação ao filho único e ao primogênito em famílias com dois filhos". Universidade Federal do Rio Grande do Sul, 2008. Apoio: Conselho Nacional de Desenvolvimento Científico e Tecnológico.

2 Universidade Federal do Rio Grande do Sul, Instituto de Psicologia. R. Ramiro Barcellos, 2600, Sala 111, Bom Fim, 90035-003, Porto Alegre, RS, Brasil. Correspondência para/Correspondence to: A.P.C.O. FREITAS. E-mail: <anapaulapsi@gmail.com>. 
A família, como primeiro meio social do qual o indivíduo participa ao longo de seu desenvolvimento, tem entre suas tarefas a socialização (Biasoli-Alves, 1997; Nichols \& Schwartz, 1998; Szymanski, 2004; Velásquez, 1997). É primeiramente a partir desse grupo que a criança deve internalizar as normas culturais e estabelecer os nexos básicos para o desenvolvimento ulterior (Biasoli-Alves, 1997). As fronteiras entre os subsistemas que constituem a família e suas interações são mediadas por regras implícitas e explícitas a fim de manter o equilíbrio familiar (Minuchin, 1985; Nichols \& Schwartz, 1998).

A concepção de criança bem como seu espaço na família são influenciados historicamente pelas transformações sociais e de valores (Biasoli-Alves, 1997). Tais transformações acabam por afetar diretamente o ciclo de vida familiar e, por conseguinte, as tarefas de socialização. O nascimento dos filhos é um importante representante disso, na medida em que as relações que se estabelecem no sistema familiar são recíprocas. Portanto, as crianças exercem influência ativa nas relações com os genitores (Belsky, 1984; Biasoli-Alves, 1997; Brody, 2004; Dessen, 1997). Assim, a personalidade e o bem-estar psicológico dos genitores, as características da criança e o contexto social estão entre os fatores destacados como principais determinantes que influenciam a forma como eles lidam com os filhos (Belsky, 1984; Dessen, 1997). Mães e pais exercem importante papel no que diz respeito à introdução de princípios morais, a fim de que a criança desenvolva comportamentos que possibilitem a aquisição de independência, autonomia e responsabilidade (Alvarenga \& Piccinini, 2001; Salvo, Silvares \& Toni, 2005). As estratégias utilizadas pelos genitores para orientar os comportamentos dos filhos no processo de socialização são denominadas práticas educativas parentais (Hoffman, 1975, 1994; Newcombe, 1999).

Considerando a influência do período evolutivo da criança nas práticas educativas, Hoffman (1975) sugeriu haver uma mudança no que diz respeito às interações entre genitores e filhos ao longo do desenvolvimento. Para o autor, os genitores passariam de cuidadores - durante a primeira infância, preocupados substancialmente com a satisfação das necessidades da criança - a agentes de socialização por volta do segundo ano de vida, tornando-se a disciplina o fator proeminente na interação com a criança.
Hoffman $(1975 ; 1994)$ classificou as práticas educativas parentais em duas categorias: estratégias indutivas e estratégias de força coercitivas. As estratégias indutivas foram caracterizadas pela obtenção do objetivo disciplinar, mediante a indicação à criança quanto às consequências de seu comportamento, enfatizando os aspectos lógicos da situação. Assim, podem favorecer a criança, pela compreensão das implicações de suas ações e, consequentemente, dos motivos que justificam a necessidade de mudança de comportamento. Nesse sentido, tais técnicas estimulam a aquisição da autonomia pela criança, que poderá utilizar a informação para controlar seu próprio comportamento, facilitando a internalização dos padrões morais. Já as estratégias de força coercitivas podem ser observadas quando da aplicação direta de força, incluindo punição física, privação de privilégios e afeto, ou uso de ameaças. Essas técnicas podem ocasionar na criança emoções intensas, como medo, raiva e ansiedade, que tendem a reduzir a possibilidade de entendimento da situação e de modificação de comportamento. Portanto, as estratégias de força coercitivas podem não favorecer a internalização de padrões morais pelas crianças, na medida em que seu comportamento é controlado fundamentalmente por punições do meio externo.

As práticas educativas exercem importante influência sobre o desenvolvimento socioemocional e sobre o comportamento da criança na família enquanto sistema (Cia, Pereira, Z.A.P. Del Prette \& A. Del Prette, 2006; Dessen, 1997; Minuchin, 1985). Nesse contexto, tanto os pais quanto as mães parecem contribuir de maneira decisiva para o desenvolvimento dos filhos, sendo que a interação de cada um com a criança difere em conteúdo e qualidade (Cia et al., 2006; Dessen, 1992; 1997). A presença das mães foi apontada como mais marcante quanto às práticas educativas no ambiente familiar se comparada aos pais (Costa, Teixeira \& Gomes, 2000). Em contrapartida, o estudo de Piccinini, Frizzo, Alvarenga, Lopes e Tudge (2007) sugere que, em se tratando de práticas educativas parentais, a questão do gênero pode ser menos relevante se considerados fatores como nível de instrução, qualidade da relação conjugal e experiência dos pais com seus próprios cuidadores. Nesse sentido, um aspecto que merece atenção diz respeito à comunicação entre pais e filhos. Sobre isso, Cia et al. (2006) destacaram que as mães que participaram 
de seu estudo relataram, com frequência significativamente maior que os pais, o comportamento dos filhos de desafiar regras. Para os autores, esse dado pode ser um indicador de que, embora pais e mães apresentem ultimamente a tendência de dividir tarefas com relação aos filhos, os pais sejam responsáveis pelas técnicas disciplinares, estando mais vinculados à ideia de autoridade, enquanto as mães, ainda que trabalhem fora, fiquem responsáveis pelos cuidados com os filhos.

Outro aspecto também apontado como influente nas práticas educativas é o número de filhos (Fox, Platz \& Bentley, 1995). Sendo assim, tratamentos diferentes podem ser destinados a diferentes filhos dentro de uma mesma família. As características de personalidade das crianças bem como seu momento evolutivo são fatores que podem fazer com que as respostas maternas variem de acordo com as habilidades de comunicação, necessidades e demandas peculiares à idade de cada filho (Dunn, Plomin \& Daniels, 1986).

Além disso, as experiências parentais com o filho mais velho também podem influenciar as expectativas e práticas educativas consideradas efetivas com os filhos subsequentes (Brody, 2004). À medida que a família aumenta, há uma dissolução dos recursos parentais, tanto com relação ao tempo quanto em relação aos recursos materiais investidos na criança (Downey, 2001). Assim, se por um lado o nascimento de um irmão pode ser entendido como uma fonte potencial de benefícios para o desenvolvimento socioemocional do primogênito (Dessen, 1997), por outro, a diminuição da atenção da mãe em função dos cuidados com o bebê (Dessen, 1997; Kendrick \& Dunn, 1980; Kowaleski-Jones \& Dunifon, 2004; Oliveira, 2005; Pereira, 2006) pode provocar no outro manifestações de ciúme e comportamentos agressivos (Griffin \& de la Torre, 1985). Isso pode acarretar um aumento de restrições e proibições da mãe para com esse filho (Kendrick \& Dunn, 1980). Ainda a esse respeito, DeaterDeckard, Smith, Ivy e Petril (2005) observaram que crianças que apresentaram mais problemas de comportamento eram tratadas pelos genitores com mais negativismo. O estudo de Alvarenga e Piccinini (2001), que investigou práticas educativas maternas e problemas de comportamento em pré-escolares, também apresentou resultados na mesma direção. Os autores constataram que mães de crianças que apresentavam problemas de externalização faziam mais uso de práticas coercitivas do que mães de crianças sem problema de comportamento.

Retomando a ideia de que todos os membros afetam as relações familiares e são por ela afetados, alguns autores (Biasoli-Alves, 1997; Brody, 2004; Hoffman, 1975) destacaram a importância de que a criança seja vista não como um receptor completamente passivo, mas um participante ativo que pode ter influência sobre o comportamento parental. Para Brody (2004), crianças com personalidade mais ativa ou emocionalmente intensa receberiam atenção diferente, usualmente mais negativa do que as crianças com personalidade calma e de temperamento fácil. Nesse sentido, Grusec e Kuczynski (1980) destacaram que as práticas educativas que as mães de crianças de 4 a 5 anos e de 7 a 8 anos dizem utilizar são substancialmente determinadas pela natureza da necessidade da criança.

A ordem de nascimento, bem como o fato de ter ou não irmãos, é outro aspecto que merece atenção enquanto fator potencialmente determinante das práticas educativas parentais. Herrera, Zajonc, Wieczorkowska e Cichomski (2003) sugerem que crenças e estereótipos sobre a ordem de nascimento podem ter importantes consequências psicológicas, comportamentais e sociais ao induzirem diferentes expectativas dos pais quanto a atributos, habilidades e comportamentos dos filhos. A reação peculiar das pessoas para com crianças de diferentes ordens de nascimento poderia reforçar e modelar os comportamentos infantis, a fim de corresponder aos estereótipos derivados disso.

O estudo de Mussun-Miller (1993) investigou os efeitos da ordem de nascimento na percepção dos genitores sobre seus filhos e crianças em geral. Segundo os resultados, os primogênitos foram descritos como mais obedientes, mais extrovertidos e menos mimados, se comparados a filhos únicos e caçulas, enquanto os filhos únicos foram descritos como crianças menos cativantes, ainda que tivessem mais disposição acadêmica. Na mesma direção, outros estudos reforçam o estereótipo de filhos únicos como crianças com habilidades sociais muitas vezes aquém do esperado, como baixa autoestima e poucos amigos (Rivera \& Carrasquillo, 1997), além de solitários, egoístas e dependentes (Falbo \& Polit, 1986; Mancillas, 2006; Polit \& Falbo, 1987). Entretanto, pouco se sabe sobre as diferenças de práticas de socialização que afetam crianças com e sem irmãos. 
O estudo de Rosenberg e Hyde (1993) examinou essas práticas de mães e pais para com seus filhos, com e sem irmãos. Não foram encontradas diferenças entre pais e mães no que diz respeito a encorajar independência, empreendedorismo e superproteção para meninos e meninas. Pais e mães apresentaram escores maiores em controle autoritário e superinvestimento nos filhos únicos, do que nos primogênitos. Além disso, embora não tenha sido encontrada diferença significativa, pais e mães de primogênitos apresentaram forte tendência a encorajar a independência dos filhos, enquanto os genitores de filhos únicos exerceram mais controle. Além disso, um superinvestimento parental foi verificado mais nos filhos únicos do que nos primogênitos. Ainda que os resultados tenham evidenciado algumas diferenças de tratamento entre filhos únicos e crianças que têm irmãos, os autores não destacaram somente a ordem de nascimento como determinante das práticas educativas parentais.

A divisão de atenção dos pais para com os filhos também tem sido associada ao número de filhos e à ordem de nascimento. A esse respeito, Jiao, Ji e Jing (1986) destacaram que, por não terem outras crianças, os genitores de filhos únicos poderiam concentrar sua atenção no filho único. A ausência de necessidade de divisão de atenção dos pais foi apontada por Rivera e Carrasquillo (1997) como uma das grandes vantagens de não ter irmãos. Segundo as autoras, poderia haver um incremento na autoestima dessas crianças se comparadas às que tem irmãos, por receberem mais reforços positivos e elogios dos pais e parentes. Além disso, por conviverem mais com adultos no ambiente doméstico, filhos únicos tenderiam a aprender mais rapidamente a linguagem e os comportamentos adultos.

As implicações das experiências da criança com cada genitor podem ser mais bem entendidas no contexto da experiência com os dois genitores (McHale, Crouter, McGuire \& Updegraff, 1995). Estudos sugerem haver diferenças especialmente em conteúdo e qualidade no que diz respeito às interações de mães e pais com relação aos filhos (Cia et al., 2006; Dessen, 1992; 1997). A partir da concepção de família enquanto sistema em constante transformação, pode-se pensar que, do ponto de vista das práticas educativas parentais, é consenso que as crianças têm papel ativo que pode influenciar no comportamento parental (Biasoli-Alves,
1997; Brody, 2004; Hoffman, 1975), o que pode vir, portanto, a interferir nas práticas educativas de acordo com o número de filhos e a ordem de nascimento.

Sendo assim, o tamanho da família e o momento do ciclo vital familiar podem repercutir de forma peculiar em vários aspectos do desenvolvimento de seus membros. Nesse sentido, o número de filhos também pode ser considerado um dos possíveis determinantes das práticas educativas. Ainda que a literatura aponte a ordem de nascimento como um fator que pode exercer influência nas práticas educativas parentais, os estudos revisados não contemplam esse aspecto, especialmente em se tratando de comparações de famílias com filho único e famílias com mais de um filho. Evidências empíricas, como as do estudo de Rosenberg e Hyde (1993), apontam que as práticas de socialização dirigidas a filhos únicos não apresentam necessariamente características negativas, quando comparadas com aquelas dirigidas a crianças que têm irmãos. Portanto, parece pertinente o estudo das práticas educativas parentais dirigidas aos filhos únicos e primogênitos de famílias com dois filhos. A relevância do presente estudo reside tanto na possibilidade de verificar eventuais repercussões nas práticas educativas parentais para com o primogênito frente ao nascimento do segundo filho, quanto no exame das estratégias educativas aplicadas ao filho único que, mesmo contrariando evidências empíricas, com frequência é vítima de estereótipos negativos. Sendo assim, o objetivo deste estudo foi investigar eventuais diferenças nas práticas educativas parentais em relação ao filho único e ao primogênito em famílias com dois filhos. Partiu-se da hipótese de que mães e pais de filhos únicos tenderiam a fazer uso mais frequente de práticas educativas indutivas para com os seus filhos, enquanto mães e pais de primogênitos de famílias com dois filhos tenderiam a fazer uso de práticas educativas coercitivas com mais frequência.

\section{Método}

\section{Participantes}

Participaram do estudo 22 famílias, das quais 12 constituídas de pai, mãe e um único filho e 10 constituídas de pai, mãe e dois filhos, tendo o segundo deles um ano de idade. Todas as famílias residiam em Porto 
Alegre e eram de nível socioeconômico médio-alto $(n=13)$ e alto ( $n=9)$, com base em Hollingshead (1975; adaptado por Tudge \& Frizzo, 2002). A idade dos filhos únicos variou entre 4,6 e 6,1 anos (Média - M=5,5, Desvio-Padrão - DP=0,51), e a dos primogênitos, entre 4,3 e 6,3 anos $(M=5,1, D P=0,78)$. Quanto ao gênero, 58,3\% dos filhos únicos eram do gênero masculino, enquanto $50,0 \%$ dos primogênitos eram do gênero masculino. A idade das mães de filho único variou entre 26 e 43 anos $(M=35,58, D P=4,68)$, enquanto a dos pais variou entre 26 e 45 anos ( $M=38,25, D P=5,33)$. Já a idade das mães de dois filhos variou entre 29 e 43 anos $(M=33,80, D P=3,68)$ e a dos pais, entre 30 e 47 anos ( $M=35,50, D P=4,67)$.

Todas as famílias selecionadas fazem parte do "Estudo longitudinal sobre o impacto do nascimento do segundo filho na dinâmica familiar e no desenvolvimento emocional do primogênito - ELSEFI" (Piccinini, Lopes, Rossato \& Oliveira, 2005). O estudo acompanha 53 famílias, das quais 29 com dois filhos e 24 com filho único, e busca investigar diversos aspectos da dinâmica de famílias com filho único e com mais de um filho, sendo que as práticas educativas constituem um dos temas examinados. As famílias dos dois grupos foram recrutadas por indicação e em escolas de educação infantil que os primogênitos e filhos únicos frequentavam, sendo que as famílias com dois filhos iniciaram sua participação quando as mães estavam no terceiro trimestre de gestação do segundo filho. As famílias dos dois grupos participaram das mesmas coletas de dados, com exceção da etapa da gestação, que só ocorreu com as famílias em que as mães estavam grávidas do segundo filho. Buscou-se parear os dois grupos considerando, em especial, a idade e gênero do primogênito e dos filhos únicos.

O ELSEFI foi aprovado pelo Comitê de Ética em Pesquisa da Universidade Federal do Rio Grande do Sul (Processo n 2004/373), tendo seguido os princípios da Resolução no 016/2000 do (Conselho Federal de Psicologia, 2000) e a Resolução no 196/96 do (Conselho Nacional de Saúde, 1996), que regulamentam a realização de pesquisas com seres humanos. Através do Termo de Consentimento Livre e Esclarecido (Grupo de Interação Social, Desenvolvimento e Psicopatologia -
GIDEP, 2006a), os participantes foram informados dos objetivos do estudo, possibilitando a decisão livre e informada sobre participar ou não.

\section{Instrumentos}

Foi utilizado um delineamento de grupos contrastantes (C. Nachmias \& D. Nachmias, 1996), envolvendo os dois grupos de famílias acima descritos, visando investigar eventuais diferenças nas práticas educativas parentais em relação ao filho único e ao primogênito em famílias com dois filhos.

Para coleta de dados, foi inicialmente utilizada a entrevista de dados demográficos do casal (GIDEP, 2006b), que visou obter dados sobre a idade, escolaridade, religião, trabalho, grupo étnico e contato dos genitores. Num segundo momento foi utilizada a Entrevista sobre Práticas Educativas Parentais (Piccinini \& Alvarenga, 2000), que buscou identificar os tipos de práticas educativas utilizadas pelos genitores. Trata-se de uma entrevista estruturada, composta de seis situações cotidianas que tendem a gerar situações de desobediência da criança, tais como: recusar-se a comer; não querer vestir a roupa escolhida pela mãe; não querer ir à escola; não querer dormir; não querer tomar banho; e fazer birra. Após mencionar cada situação, foram investigadas as práticas educativas parentais. Por fim, o genitor era solicitado a relatar espontaneamente outras situações do dia a dia em que encontrava dificuldades em lidar com a criança, devendo o entrevistador explorar como foi manejada a situação, investigando as práticas da mesma maneira que nas situações estruturadas. A entrevista foi realizada separadamente com cada um dos genitores, tendo sido gravada em áudio e posteriormente transcrita para análise.

\section{Resultados}

Análise de conteúdo quantitativa e qualitativa foi utilizada para examinar as respostas dos genitores nas situações investigadas na referida entrevista (Bardin, 1977). A análise quantitativa ${ }^{3}$ foi utilizada para analisar

\footnotetext{
$\nabla \nabla \nabla \nabla$
}

$\mathbf{3}$ Em função de não terem sido encontradas diferenças estatisticamente significativas em relação aos dados apresentados nas Tabelas 1 e 2 , não são apresentados os valores do teste nas referidas tabelas. 
as frequências de respostas dos genitores, enquanto a análise qualitativa visou compreender particularidades e semelhanças de respostas entre e dentro de cada grupo. As práticas educativas identificadas foram classificadas utilizando-se a seguinte estrutura de categorias e subcategorias derivadas da literatura (Alvarenga \& Piccinini, 2001; Hoffman, 1975, 1994; Piccinini et al., 2003; Piccinini et al., 2007): Práticas indutivas: a) negociação/troca; b) explica/fala; c) explicação baseada em convenções ou consequências; d) organização do ambiente; e) comando verbal não coercitivo; Práticas coercitivas: a) punição; b) ameaça; c) coação física; d) punição física; e Não interferência: a) não intromissão; b) segue ao ritmo da criança; c) cede à vontade da criança.
Dois juízes classificaram separadamente todas as respostas das mães e pais, chegando-se a um índice médio de concordância de 0,94, sendo 0,84 para práticas indutivas, 0,99 para práticas coercitivas e 1,0 para não interferência. Num segundo momento, eventuais discordâncias entre os juízes foram dirimidas por discussão.

A Tabela 1 apresenta os percentuais e frequências das respostas sobre práticas educativas maternas com relação ao filho único e ao primogênito. Com relação aos resultados envolvendo filho único, pode-se observar maior frequência no uso de práticas educativas indutivas pelas mães de filho único em todas as situações investigadas: hora de dormir (73\%), escola (70\%), roupa (59\%), alimentação (50\%), banho (50\%), birra (48\%).

Tabela 1. Percentuais e frequências das respostas sobre práticas educativas maternas em relação ao filho único - U - (n=12) e ao primogênito - $P$ - ( $n=10)$. Porto Alegre (RS), 2008.

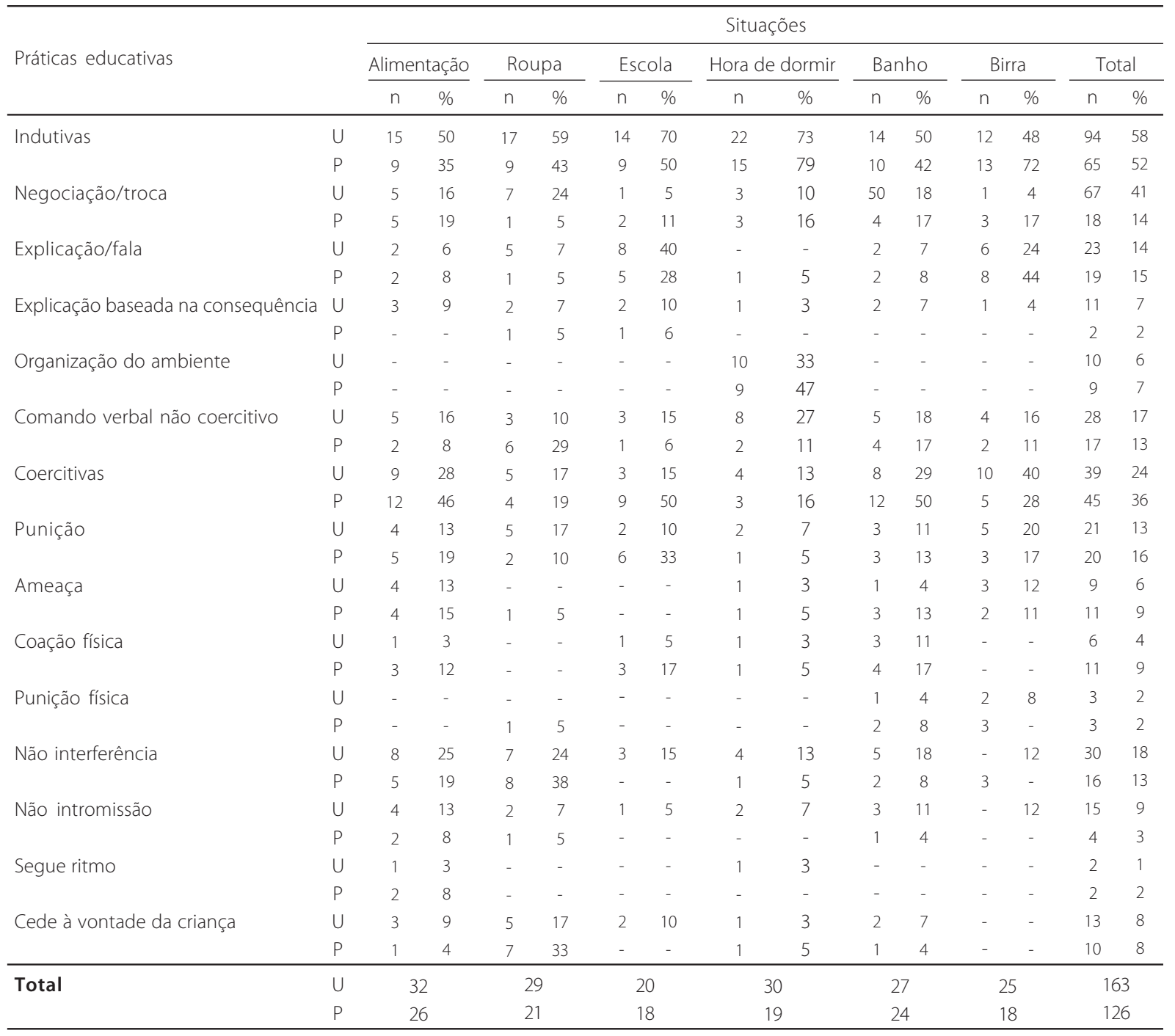


Contudo, as mães de filho único, embora tenham relatado inicialmente o uso de práticas indutivas, não hesitavam em passar a usar práticas coercitivas quando ele não obedecia: "Sempre tem uma negociação na hora do banho....jáprecisei contar de um atétrês, de um atétrês e ela não vinha e 'Vou te puxar pelos cabelos!' Então ela corre rapidinho evem" (MU2)4. O fato de ter uma única criança para cuidar também foi mencionado como facilitador por uma das mães, no sentido de permitir maior flexibilidade frente à situação de desobediência do filho: "Se tivesse mais de dois pra dar banho, eu não ia ter maleabilidade" (MU8).

Já em relação aos primogênitos, observando os dados da Tabela 1, pode-se perceber que as mães mencionaram o uso de práticas indutivas com mais frequência nas situações hora de dormir (79\%), birra (72\%) e roupa (43\%), enquanto o uso de práticas coercitivas foi descrito com mais frequência nas situações banho (50\%) e alimentação (46\%). Na situação escola, as mães usaram com a mesma frequência práticas indutivas (50\%) e coercitivas (50\%).

Os dados da Tabela 1 sugerem diferenças na frequência de respostas entre os dois grupos de mães no uso de práticas indutivas e coercitivas. Todavia, o exame qualitativo das respostas maternas revelou, entre as mães de primogênito, a mesma tendência a optar primeiramente por práticas indutivas, passando após às coercitivas, como no grupo de mães de filhos únicos. A ida a escola é um exemplo disso: "Filha! A mãe tá atrasada! [para deixar a filha na escola e chegar ao trabalho] A mãe precisa ir, filha.... Até que eu brigo mesmo com ela" (MP16).

Uma peculiaridade verificada entre as mães de primogênito foi o uso da mesma prática educativa destinada ao primogênito e ao segundo filho simultaneamente:"AM. [segunda filha] às vezes arranca as coisas da mão da A. [primogênita] e ela não gosta. Aí, ela vai lá e arranca. Aí, a mãe já explicou que tem que pedir, que tem que ensinar a mana..." (MP 20). Outra característica marcante desse grupo de mães foi a dificuldade em dividir a atenção entre as crianças, o que evidenciou a falta de paciência da mãe para com o primogênito: "Eu digo
'Filho, não é. Éque ela [segunda filha] ébebê...'Às vezes, eu pego evou, atendo ele [primogênito] primeiro e... ou então eu digo que tem que esperar enão tem. 'Não adianta! Não posso largar o que eu tô fazendo e espera que a mãe já vai te dar.' Faço ouvido de surdo... não que eu tenha ... mas se ceder tudo, tu acaba enlouquecendo"(MP15).

Considerando os totais das práticas educativas maternas, o teste do qui-quadrado não revelou diferenças significativas entre o grupo de mães de filho único e o de primogênito. Com relação ao total de respostas, independentemente das situações, pôde-se observar que as práticas educativas indutivas foram as mais referidas pelas mães dos dois grupos, embora sejam um pouco mais frequentes entre as mães de filho único (58\%) do que de primogênito (52\%). As práticas coercitivas foram menos frequentes em ambos os grupos e apresentaram uma tendência contrária, tendo sido mencionadas pouco mais pelas mães de primogênito (36\%) do que de filho único (24\%). Por fim, não interferência foi a categoria menos mencionada em ambos os grupos, sendo mais relatada pelas mães de filho único (18\%) do que pelas mães de primogênito (13\%).

Com relação às práticas educativas paternas, foi realizado o mesmo procedimento de análise utilizado com as respostas maternas. A Tabela 2 apresenta percentuais e frequências das respostas sobre práticas educativas paternas em relação ao filho único e ao primogênito. Pôde-se observar que as práticas educativas indutivas foram relatadas como sendo usadas com mais frequência pelos pais de filho único nas situações: hora de dormir (63\%), banho (58\%) e alimentação (42\%). Já as práticas educativas coercitivas foram referidas com mais frequência nas situações escola (75\%) e roupa (40\%). Na situação birra foi observada a mesma frequência de práticas indutivas (50\%) e coercitivas (50\%).

Semelhante ao que se constatou no caso das mães, os pais de filho único referiram as práticas indutivas com maior frequência. Além disso, tal como as mães, eles denotaram a preocupação em manter sua posição frente à ação ou comportamento desejado, considerando a possibilidade de uso de prática coercitiva se necessário, conforme o exemplo: "Normalmente

\footnotetext{
- Na dissertação da qual é derivado este estudo, são apresentadas várias vinhetas que ilustram as categorias e subcategorias que, em função da restrição de espaço, não puderam aqui ser colocadas na íntegra.
} 
a gente brinca. Se ela tá emburrada, a gente brinca com ela ou a gente fica rindo. Mas às vezes, quando persiste muito, a gente acaba discutindo. Mas normalmente não" (PU9).

Os pais de primogênito, segundo os dados da Tabela 2, apresentaram relato predominante de práticas indutivas nas situações escola (62\%), hora de dormir (54\%), roupa (50\%), birra (45\%) e alimentação (43\%), enquanto as práticas coercitivas foram mais frequentes na situação banho (50\%). Semelhante ao que foi observado no grupo de pais de filho único, alguns relatos de pais de primogênito revelaram o uso inicial de práticas indutivas e, uma vez não atingido o objetivo, a opção pelo uso de prática coercitiva: "Quando ela não quer comer, de modo geral, a gente tenta procurar o que ela gosta. Mas a gente briga. Depende do dia. Aí, a gente desliga aTV, força ela a virpra mesa" (PP13).

O teste qui-quadrado não revelou diferenças significativas quanto às práticas educativas de pais de filhos únicos e de primogênitos. De acordo com os totais de respostas de práticas educativas paternas observados na Tabela 2, não houve diferenças acentuadas entre os dois grupos na distribuição das frequências das três principais práticas educativas examinadas. Contudo, os pais de primogênito (48\%) tenderam a usar um pouco mais de práticas indutivas do que pais de filho único (44\%). Já as práticas coercitivas foram um pouco mais

Tabela 2. Percentuais e frequências das respostas sobre práticas educativas paternas em relação ao filho único - $U$ - ( $n=6)$ e ao primogênito - $P$ - ( $n=8)$. Porto Alegre (RS), 2008.

\begin{tabular}{|c|c|c|c|c|c|c|c|c|c|c|c|c|c|c|c|}
\hline \multirow{3}{*}{ Práticas educativas } & & \multicolumn{14}{|c|}{ Situações } \\
\hline & & \multicolumn{2}{|c|}{ Alimentação } & \multicolumn{2}{|c|}{ Roupa } & \multicolumn{2}{|c|}{ Escola } & \multicolumn{2}{|c|}{ Hora de dormir } & \multicolumn{2}{|c|}{ Banho } & \multicolumn{2}{|c|}{ Birra } & \multicolumn{2}{|c|}{ Total } \\
\hline & & $n$ & $\%$ & $n$ & $\%$ & $n$ & $\%$ & $\mathrm{n}$ & $\%$ & $\mathrm{n}$ & $\%$ & $n$ & $\%$ & $\mathrm{n}$ & $\%$ \\
\hline \multirow[t]{2}{*}{ Indutivas } & $U$ & 6 & 42 & 3 & 20 & 2 & 25 & 5 & 63 & 7 & 58 & 6 & 50 & 29 & 44 \\
\hline & $P$ & 9 & 43 & 8 & 50 & 8 & 62 & 7 & 54 & 8 & 40 & 8 & 45 & 48 & 48 \\
\hline \multirow[t]{2}{*}{ Negociação/troca } & $U$ & 2 & 17 & 2 & 13 & - & - & 2 & 25 & 2 & 17 & 4 & 33 & 12 & 18 \\
\hline & $P$ & 5 & 24 & 3 & 19 & 2 & 15 & 2 & 15 & 2 & 10 & 3 & 17 & 17 & 17 \\
\hline \multirow[t]{2}{*}{ Explicação/fala } & $U$ & 1 & 8 & 1 & 7 & 2 & 25 & 1 & 13 & 1 & 8 & 2 & 17 & 8 & 12 \\
\hline & $P$ & 2 & 10 & 3 & 19 & 4 & 31 & 1 & 8 & 4 & 20 & 4 & 22 & 18 & 18 \\
\hline \multirow[t]{2}{*}{ Explicação baseada na consequência } & $U$ & 1 & 8 & - & - & - & - & - & - & 1 & 8 & - & - & 2 & 3 \\
\hline & $P$ & 1 & 5 & 1 & 6 & 1 & 8 & - & - & - & - & - & - & 3 & 3 \\
\hline \multirow[t]{2}{*}{ Organização do ambiente } & $U$ & 1 & 8 & - & - & - & - & 1 & 13 & - & - & - & - & 2 & 3 \\
\hline & $P$ & - & - & - & - & - & - & 2 & 15 & - & - & - & - & 2 & 2 \\
\hline \multirow[t]{2}{*}{ Comando verbal não coercitivo } & $U$ & 1 & 8 & - & - & - & - & 1 & 13 & 3 & 25 & - & - & 5 & 8 \\
\hline & $P$ & 1 & 5 & 1 & 6 & 1 & 8 & 2 & 15 & 2 & 10 & 1 & 6 & 8 & 8 \\
\hline \multirow[t]{2}{*}{ Coercitivas } & $U$ & 3 & 25 & 6 & 40 & 6 & 75 & - & - & 5 & 42 & 6 & 50 & 26 & 39 \\
\hline & $P$ & 5 & 24 & 3 & 19 & 5 & 39 & 2 & 15 & 10 & 50 & 7 & 39 & 32 & 32 \\
\hline \multirow[t]{2}{*}{ Punição } & $U$ & 2 & 17 & 4 & 27 & 4 & 50 & - & - & 4 & 33 & 2 & 17 & 16 & 24 \\
\hline & $P$ & 3 & 14 & 2 & 13 & 4 & 31 & 2 & 15 & 5 & 25 & 5 & 28 & 21 & 21 \\
\hline \multirow[t]{2}{*}{ Ameaça } & $U$ & 1 & 8 & 2 & 13 & 1 & 13 & - & - & - & - & 2 & 17 & 6 & 9 \\
\hline & $P$ & 1 & 5 & 1 & 6 & - & - & - & - & 1 & 5 & - & - & 3 & 3 \\
\hline \multirow[t]{2}{*}{ Coação física } & $U$ & - & - & - & - & 1 & 13 & - & - & 1 & 8 & - & - & 2 & 3 \\
\hline & $P$ & 1 & 5 & - & - & 1 & 8 & - & - & 4 & 20 & 1 & 6 & 7 & 7 \\
\hline \multirow[t]{2}{*}{ Punição física } & $U$ & - & - & - & - & - & - & - & - & - & - & 2 & 17 & 2 & 3 \\
\hline & $P$ & - & - & - & - & & - & - & - & - & - & 1 & 6 & 1 & 1 \\
\hline Não interferência & $U$ & 4 & 33 & 4 & 27 & & - & 3 & 38 & - & - & - & - & 11 & 17 \\
\hline Não intromissão & $P$ & 3 & 14 & 2 & 13 & - & - & 1 & 8 & - & - & 2 & 11 & 8 & 8 \\
\hline \multirow[t]{2}{*}{ Segue ritmo } & $U$ & 2 & 17 & - & - & - & - & - & - & - & - & - & - & 2 & 3 \\
\hline & $P$ & 1 & 5 & - & - & - & 1 & 8 & - & - & - & - & - & 2 & 2 \\
\hline \multirow[t]{2}{*}{ Cede à vontade da criança } & $U$ & 1 & 8 & 3 & 20 & - & - & - & - & - & - & - & - & 4 & 6 \\
\hline & $\mathrm{P}$ & 3 & 14 & 3 & 19 & - & - & 2 & 15 & 2 & 10 & 1 & 6 & 11 & 11 \\
\hline Total & $U$ & & & & & & & & & & 2 & & & & \\
\hline & $P$ & & & & & & & & & & & & & & \\
\hline
\end{tabular}


frequentes entre os pais de filho único (39\%) do que de primogênito (32\%). Por fim, a categoria não interferência foi um pouco mais frequente entre os pais de primogênito (21\%) do que entre os de filho único (17\%).

Eventuais concordâncias ou discordâncias nas práticas educativas de mães e pais dentro de cada grupo também foram investigadas. Conforme os dados da Tabela 3, as mães de filho único referiram mais uso de práticas educativas indutivas (58\%) do que os pais (44\%) desse grupo de famílias. Já com relação às práticas educativas coercitivas, foi verificada uma tendência contrária, tendo os pais (39\%) utilizado mais do que as mães (24\%) esse tipo de prática. Por fim, as mães de filho único (18\%), mais do que os pais (17\%), utilizaram práticas de não interferência. O teste qui-quadrado revelou diferença marginalmente significativa $\left(\chi^{2}=5,59\right.$; $\mathrm{DF}=2 ; p<0,07)$ no uso das práticas educativas maternas e paternas com relação ao filho único.

Apesar das diferenças no uso das práticas entre mães e pais de filho único que podem ser vistas na Tabela 3, a análise qualitativa dos relatos dos genitores de ambos os gêneros revelou uma tendência geral das mães e pais, já assinalada acima, de usarem inicialmente práticas indutivas, passando a coercitivas caso as primeiras não fossem efetivas: "Vamos sentar aqui e vamos comer.... Não quero nem saber. Tu vais comer senão tu não vais no aniversário hoje"(MU2) e "Vamos lá. Vamos comer. ... Poisé, Papai Noel tá olhando..." (PU2). Já a falta de acordo entre mãe e pai ficou evidente em situações como o banho, onde a mãe referiu uso de prática coercitiva "Eu pegava ela pelo braço e arrastava pro banheiro" (MU4), enquanto o pai referiu primeiramente o uso de prática indutiva: "Eu acho que teria que falar, conversar, dialogar um pouco..." (PU4).

Em contrapartida, no grupo de genitores de primogênito, conforme os dados da Tabela 3, verificou- -se pouca diferença no que diz respeito ao uso de práticas educativas indutivas entre as mães (52\%) e pais (48\%). Diferença um pouco maior se verificou com relação às práticas coercitivas, tendo as mães (36\%) referido um pouco mais uso desse tipo de práticas do que os pais (32\%). Já as práticas de não interferência foram utilizadas mais pelos pais (21\%) do que pelas mães (13\%). O teste do qui-quadrado não revelou diferença significativa nas práticas educativas parentais com relação ao primogênito. A análise qualitativa das práticas educativas relatadas por mães e pais de primogênito reforça os resultados apresentados na Tabela 3, confirmados pelo teste qui-quadrado, que não evidenciou diferença significativa entre as práticas educativas desses genitores. Isso pode ser verificado nas vinhetas a seguir: "Contar histórias, ficar mais tempo com ela pra que ela vá dormir" (MP13) e "Aí, tem que ir tentando argumentar" (PP13). "É pegar elevar". (MP13) e "Pega no colo, briga pra ir..."(PP13).

Os dados da Tabela 3 sugerem uma discreta diferença no uso das práticas indutivas pelas mães e pais de filho único e de primogênito. Com relação ao filho único, as mães (58\%) tenderam a usar mais práticas indutivas do que os pais (44\%), enquanto pouca diferença foi verificada entre as mães e pais com relação ao primogênito (52\% e 48\%, respectivamente). Já com relação às práticas coercitivas, no caso dos filhos únicos, os pais (39\%) tenderam a ser mais coercitivos do que as mães (24\%) enquanto pouca diferença apareceu entre mães (36\%) e pais (32\%) de primogênito. Por fim, quanto às práticas de não interferência, poucas diferenças foram verificadas com relação ao filho único, tendo mães e pais sido muito semelhantes no uso dessa prática (18\% e 17\%, respectivamente). Com relação ao primogênito, as diferenças também foram pequenas, embora opostas, tendo o pai (21\%) relatado um pouco mais dessas estratégias do que a mãe (13\%).

Tabela 3. Percentuais e frequências das práticas educativas parentais em relação ao filho único - $U$ - $(n=18)$ e ao primogênito - $P$ - ( $n=18)$. Porto Alegre (RS), 2008.

\begin{tabular}{rcrr}
\hline & & Práticas educativas parentais & \\
\cline { 2 - 4 } & & Práticas indutivas & Náticas coercitivas interferência \\
\hline Mães $U(n=12)$ & $58(94)$ & $24(39)$ & $18(30)$ \\
$P(n=10)$ & $52(65)$ & $36(45)$ & $13(16)$ \\
Pais $U(n=6)$ & $44(29)$ & $39(26)$ & $17(11)$ \\
P $(n=8)$ & $48(48)$ & $32(32)$ & $21(21)$ \\
\hline
\end{tabular}




\section{Discussão}

Os resultados do presente estudo apontaram diferença marginalmente significativa somente entre mães e pais em relação ao filho único, revelando uma tendência ao uso predominante de práticas indutivas pelas mães e coercitivas pelos pais. Portanto, a hipótese inicial não foi corroborada. De maneira geral, nos dois grupos de genitores ficou evidente que as práticas educativas variaram nas diferentes situações analisadas. Mães e pais de filho único e de primogênito apresentaram a tendência em usar primeiramente a prática indutiva, passando à coercitiva quando não atingido o objetivo disciplinar. Tal achado corrobora a noção de que a criança não é mero receptor das práticas educativas, sendo essas substancialmente determinadas pela natureza da situação e pela necessidade da criança (Grusec \& Kuczynski, 1980). Além disso, segundo os resultados do presente estudo, o fato de ter um irmão não implica necessariamente o uso predominante de práticas coercitivas, como sugeria a literatura (Kendrick \& Dunn, 1980). Nesse sentido, a ordem de nascimento representa apenas um dos fatores que podem determinar diferentes respostas dos genitores com relação a cada filho (Dunn \& Kendrick, 1981).

Com relação às práticas educativas maternas, ainda que as mães de primogênito que participaram do presente estudo tenham evidenciado, em alguns momentos de seus relatos, a falta de paciência para com eles, isso não impediu que explicassem ao filho mais velho a necessidade de mais atenção para com o irmão menor, incapaz de executar ações que ele já executava sozinho. Mesmo que neste estudo não tenham sido encontradas diferenças significativas entre práticas educativas maternas dos dois grupos, mães de filho único referiram o uso predominante de práticas indutivas, enquanto as mães de primogênito dividiram-se entre o uso de práticas tanto coercitivas quanto indutivas nas situações investigadas. Pode-se supor que este achado tenha relação com a questão do tempo que a mãe despende com os filhos, na medida em que os genitores de filho único não precisam dividir seu tempo e recursos com mais de um filho (Downey, 2001), enquanto os genitores de primogênitos, especialmente a mãe, experimentariam a redução do tempo em função dos cuidados com o bebê (Dessen, 1997; Kendrick \& Dunn, 1980; Kowaleski-Jones \& Dunifon, 2004; Oliveira, 2006;
Pereira, 2006). A análise qualitativa das falas maternas do presente estudo mostrou que ter um único filho foi considerado pelas mães como um facilitador no sentido de flexibilidade frente a situações de desobediência. A esse respeito, a literatura é divergente. Se, por um lado, não ter de dividir atenção com os pais é apontado como vantagem de ser filho único (Rivera \& Carrasquillo, 1997), o estudo de Doh e Falbo (1991) não revelou diferenças entre mães de filho único e mães de mais de um filho em termos de atenção e superproteção. De qualquer maneira, o uso frequente de práticas educativas indutivas nos dois grupos de mães que participaram deste estudo corrobora os achados de outros dois estudos brasileiros realizados com crianças da mesma faixa etária (Alvarenga \& Piccinini, 2001; Piccinini et al., 2003).

No que se refere às práticas educativas paternas, a exemplo das maternas, os resultados deste estudo não apresentaram diferenças significativas. À semeIhança das mães, a flexibilidade com relação ao uso de diferentes práticas educativas pelos pais, nas diferentes situações investigadas, reforça a ideia de que as práticas variam de acordo com características da criança e a natureza da situação (Grusec \& Kuczynski, 1980). Enquanto os pais de filho único revelaram uso relativamente equilibrado de práticas indutivas e coercitivas, 0 relato de uso predominante de práticas indutivas entre pais de primogênito pode ser entendido como uma tentativa de compensação à divisão do tempo materno para com o segundo filho (Dessen, 1997; Kendrick\&Dunn, 1980; Kowaleski-Jones \& Dunifon, 2004; Oliveira, 2006; Pereira, 2006), bem como ao aumento de restrições e proibições da mãe para com o primogênito (Kendrick \& Dunn, 1980).

No que tange à comparação das práticas educativas parentais, a literatura aponta que, se comparada aos pais, a presença das mães é, de fato, mais marcante (Costa, Teixeira \& Gomes, 2000). Ainda que se verifique hoje um maior envolvimento dos pais com as crianças (Dessen, 1992; Tudge et al., 2000), a questão dos cuidados ainda é assumida na maior parte das vezes pela mãe (Alonso, Wagner \& Castellá, 2006; Dessen, 1992; Tudge et al., 2000). Nesse sentido, a frequência maior de práticas indutivas entre mães de filho único, e de coercitivas entre os pais, pode estar associada à ideia de que o cuidado ainda está mais atrelado à figura materna 
enquanto a autoridade, à paterna. Outra possibilidade seria a tentativa dos pais de compensar a indutividade das mães com o intuito de impor limites mais rígidos aos filhos únicos. Já quanto às práticas educativas parentais em relação ao primogênito, o fato de não terem sido encontradas diferenças significativas entre mães e pais leva a inferir sobre uma maior parceria do casal quanto à educação dos filhos, como encontraram Cia et al. (2006). A concordância de práticas educativas parentais em relação ao primogênito verificada neste estudo corrobora também os achados de McHalle, Crouter, McGuire e Updegraff (2005). Ainda que a análise tenha sido realizada considerando a frequência de respostas e não caso a caso separadamente, dada a diferença marginalmente significativa evidenciada nas práticas educativas parentais em relação ao filho único e a concordância entre mães e pais de primogênito, pode-se pensar no fato de ter mais de um filho como um fator que contribui para a congruência das práticas.

Sobre fatores eventualmente relacionados às práticas educativas, mães e pais tendem a responder de forma diferente a cada filho (Dunn \& Kendrick, 1981). Nessa perspectiva, gênero e idade podem ser determinantes das atribuições que os genitores esperam de cada filho, relacionando-se, por conseguinte, às razões para comportamentos das crianças e respostas parentais (Mussun-Miller, 1993). Sendo assim, do ponto de vista da criança, ter um irmão poderia representar a garantia de um lugar especial na família. O primogênito de gênero diferente do segundo filho, por exemplo, não necessitaria de esforços concentrados para garantir a atenção dos genitores, seguindo, de certa forma, filho único, pelo menos daquele gênero.

Tomando os comportamentos infantis como um dos determinantes das práticas educativas parentais (Biasoli-Alves, 1997; Brody, 2004; Hoffman, 1975), se, de fato, os filhos únicos correspondem ao estereótipo negativo, as práticas educativas referidas com mais frequência deveriam ser as coercitivas, dado que crianças que apresentam problemas de comportamento tendem a ser tratadas com mais negativismo pelos pais (Deater-Deckard et al., 2005). Contudo, os resultados do presente estudo não corroboram essa afirmação. Cabe ressaltar que os comportamentos infantis foram acessados apenas por uma entrevista com os genitores, que eviden- ciou o relato predominante do uso de práticas indutivas no grupo de genitores de filho único. Sendo assim, fica em aberto a discussão sobre se o eventual bom comportamento das crianças favoreceria a indutividade ou se haveria, de fato, dificuldade dos genitores em impor limites, visto que, segundo eles, na maior parte das vezes teria sido atingido o objetivo disciplinar.

Por fim, o fato de não terem sido encontradas diferenças significativas com relação às práticas educativas parentais em relação ao filho único e ao primogênito corrobora a literatura no sentido de que as práticas não constituem um processo unilateral (Grusec \& Kuczynski, 1980). Os dados do presente estudo reforçam essa ideia, na medida em que as práticas educativas de ambos os grupos variaram de acordo com a situação investigada e o comportamento emitido pela criança. Isso sugere que seja arriscado classificar, a priori, os genitores numa ou noutra categoria de práticas. É prudente que sejam investigadas as respostas parentais às diversas situações. Portanto, o número de filhos e a ordem de nascimento constituem apenas duas variáveis passíveis de consideração, entre tantas outras potencialmente determinantes das práticas educativas parentais.

Além disso, deve-se ainda atentar para algumas questões de cunho metodológico que podem ter interferido nos resultados do presente estudo. Uma vez que se assume que as práticas educativas constituem um evento recíproco na relação entre genitores e filhos, o instrumento utilizado para a coleta de dados pode não ter sido suficientemente sensível para avaliar a dinâmica entre as partes, pois só obteve dados referentes ao relato parental. Soma-se a isso o fato de a entrevista mencionar situações previamente estruturadas para investigar basicamente situações cotidianas de desobediência. Contudo, em defesa deste instrumento, também utilizado em outros estudos (Alvarenga \& Piccinini, 2001; Piccinini et al., 2003; Piccinini et al., 2007), pode-se pensar que ele contempla as principais situações que evidenciam o uso das práticas educativas, dada a baixa frequência de relato de outras situações que também foram solicitadas aos genitores, na última seção do instrumento. Outro aspecto importante com relação ao instrumento diz respeito ao fato de que genitores referiram não ter vivenciado alguma das situações 
estruturadas sugeridas, emitindo respostas hipotéticas. Nesses casos, alguns dos participantes enfatizaram que só poderiam relatar exatamente o que fariam caso passassem realmente pela situação examinada na entrevista. De qualquer modo, o uso de situações hipotéticas tem sido referido na literatura, e as respostas a elas se assemelham às situações reais. Dadas tais limitações, sugere-se que novos estudos utilizem outras formas de coleta de dados, tais como a observação da interação familiar ou mesmo o relato das próprias crianças, confrontando-o com o relato parental, na tentativa de apreender as perspectivas dos diferentes membros da família envolvidos nas práticas educativas.

Outro aspecto relevante é a questão da desejabilidade social, que pode ter aumentado a tendência dos genitores em dar respostas socialmente aceitas (Anastasi \& Urbina, 2000). Por saberem estar participando de uma pesquisa, mães e pais podem ter respondido com base no que julgam que seria socialmente considerado adequado, destacando o uso predominante de práticas indutivas e omitindo o uso das coercitivas. Assim, é provável que tanto mães quanto pais possam ser mais coercitivos e menos indutivos do que se mostraram no presente estudo, dado que socialmente não é bem visto o relato de práticas coercitivas.

\section{Considerações Finais}

Por fim, a opção pelo delineamento de grupos contrastantes, utilizando filhos únicos como um grupo natural de comparação ao de primogênitos, procurou contemplar eventuais diferenças com relação à ordem de nascimento e ao número de filhos. A esse respeito, vale destacar a dificuldade em, no contexto atual, recrutar famílias intactas constituídas de mãe, pai e filho, o que explica o pequeno número de famílias analisadas.

Assim, os achados do presente estudo trazem uma nova contribuição à literatura, ao se propor a compreender as práticas educativas parentais em relação ao filho único e ao primogênito. As práticas educativas parentais constituem uma importante área de investigação, na medida em que operam de maneira decisiva não só no desenvolvimento infantil, mas no desenvolvimento parental e no ciclo de vida familiar. Ainda que se reconheça a importância da ordem de nascimento e do número de filhos como fatores poten- cialmente determinantes das práticas educativas, são escassos os estudos que abordam esse tópico ainda na infância. Isso, somado à análise da extensão de aspectos positivos e negativos associados às diferentes ordens de nascimento, merece a atenção de novos estudos. Espera-se que este trabalho possa contribuir no sentido de oferecer subsídios para entender melhor as famílias com um ou mais filhos, favorecendo intervenções mais eficazes que propiciem o desenvolvimento do sistema familiar como um todo, e de cada um de seus membros individualmente.

\section{Referências}

Alvarenga, P., \& Piccinini, C. A. (2001). Práticas educativas maternas e problemas de comportamento em pré-escolares. Psicologia: Reflexão e Crítica, 14 (3), 449-460.

Alonso, L., Wagner, A., \& Castellá (2006). Prácticas educativas em famílias brasileñas de nível sócio-económico bajo. Cultura y Educación, 18 (1), 69-81.

Anastasi, A., \& Urbina, S. (2000). Testagem psicológica. Porto Alegre: Artes Médicas.

Bardin, L. (1977). Análise de conteúdo. Lisboa: Edição 70.

Belsky, J. (1984). The determinants of parenting: a process model. Child Development, 55, 83-54.

Biasoli-Alves, Z. M. M. (1997). Famílias brasileiras do século XX: os valores e as práticas de educação da criança. Temas em Psicologia, 5 (3), 33-49.

Brody, G. H. (2004). Sibling's direct and indirect contributions to child development. Current Directions in Psychological Sciences, 13 (3), 124-126.

Cia, F., Pereira, C. S., Del Prette, Z. A. P., \& Del Prette, A. (2006). Habilidades sociais parentais e o relacionamento entre pais e filho. Psicologia em Estudo, 11 (1), 73-81.

Conselho Federal de Psicologia. (2000). Resolução no 016/ 2000. Brasília: Autor.

Conselho Nacional de Saúde. (1996). Resolução no 196/1996. Brasília: Autor.

Costa, F. T, Teixeira, M. A. P., \& Gomes, W. B. (2000). Responsividade e exigência: duas escalas para avaliar estilos parentais. Psicologia: Reflexão e Crítica, 13 (3), 465-473.

Deater-Deckard, K., Smith, J. Ivy, L., \& Petril, S. A. (2005). Differential perceptions of and feelings about sibling children: implications for research on parenting stress. Infant and Child Development, 14 (2), 211-225.

Dessen, M. A. S. C. (1992). Efeitos do nascimento de uma segunda criança no comportamento e nas relações entre o primogênito e os genitores. Tese de doutorado não-publicada, Universidade de São Paulo.

Dessen, M. A. (1997). Desenvolvimento familiar: transição de um sistema triádico para um sistema poliádico. Temas em Psicologia, 5 (3), 51-61. 
Doh, H. S., \& Falbo, T. (1999). Social competence, maternal attentiveness, and overprotectiveness: only child in Korea. International Journal of Behavioral Development, 23 (1), 149-162.

Downey, D. B. (2001). Number of siblings and intellectual development: the resource dilution explanation. American Psychologist, 56 (6/7), 497-504.

Dunn, J., \& Kendrick, C. (1981). Interaction between young siblings: association with the interaction between mother and first born child. Developmental Psychology, 17 (3), 336-343.

Dunn, J., Plomin, R., \& Daniels, D. (1986). Consistency and change in mothers' behavior toward young siblings. Child Development, 57 (2), 348-356.

Falbo, T., \& Polit, D. F. (1986). Quantitative review of the only child literature: research evidence and theory development. Psychological Bulletin, 100 (2), 176-189.

Fox, R. A., Platz, D. L., \& Bentley, K. S. (1995). Maternal factors related to parenting practices, developmental expectations, and perceptions of child behavior problems. Journal of Genetic Psychology, 156 (4), 431-441.

Griffin, E. W., \& de la Torre, C. (1985). New baby in the house: sibling jealousy. Medical Aspects of Human Sexuality, 19 (3), 110-116.

Grupo de Interação Social, Desenvolvimento e Psicopatologia, Núcleo de Infância e Família. (2006a). Termo de consentimento livre e esclarecido. Manuscrito não-publicado, Universidade Federal do Rio Grande do Sul, Porto Alegre.

Grupo de Interação Social, Desenvolvimento e Psicopatologia, Núcleo de Infância e Família. (2006b). Entrevista de dados demográficos. Manuscrito não-publicado, Universidade Federal do Rio Grande do Sul, Porto Alegre.

Grusec, J. E., \& Kuczynski, L. (1980). Direction of effect in socialization: a comparison of the parent's versus the child's behavior as determinants of disciplinary techniques. Developmental Psychology, 16 (1), 1-9.

Herrera, N. C., Zajonc, R. B., Wieczorkowska, G., \& Cichomski, B. (2003). Beliefs about birth rank and their reflection in reality. Journal of Personality and Social Psychology, 85 (1), 142-150.

Hoffman, M. L. (1975). Moral internalization, parental power and the nature of parent-child interaction. Developmental Psychology, 11 (2), 228-239.

Hoffman, M. L. (1994). Discipline and internalization. Developmental Psychology, 30, 26-28.

Jiao, S., Ji, G., \& Jing, Q. (1986). Comparative study of behavioral qualities of only children and sibling children. Child Development, 57 (2), 357-361.

Kendrick, K., \& Dunn, J. (1980). Caring for a second baby: effects on interaction between mother and first born. Developmental Psychology, 16 (4), 303-311.

Kowaleski-Jones, L., \& Dunifon, R. (2004). Children's home environments: understanding the role of family structure changes. Journal of Family Issues, 25 (1), 3-28.
Mancillas, A. (2006). Challenging the stereotypes about only children: a review of the literature and implications for practice. Journal of Counseling \& Development, 84 (3), 268-275.

McHalle, S. M., Crouter, A. C., McGuire, S. A., \& Updegraff, K. A. (1995). Congruence between mothers' and fathers' differential treatment of siblings: links with family relations and children's well-being. Child Development, 66 (1), 116-128.

Minuchin, P. (1985). Families and individual development: provocations from the field of family therapy. Child Development, 56 (2), 289-302.

Mussun-Miller, L. (1993). Sibling status effects: parents' perceptions of their own children. Journal of Genetic Psychology, 154 (2), 189-198.

Nachmias, C., \& Nachmias, D. (1996). Research methods in the social sciences. London: Arnold.

Newcombe, N. (1999). Socialização no cenário da família. In N. Newcombe (Org.), Desenvolvimento infantil:abordagem de Mussen (pp.336-363). Porto Alegre: Artes Médicas.

Nichols, M. P., \& Schwartz, R. C. (1998). Primeiros modelos e técnicas básicas: processos de grupo e análises das comunicações. In M. P. Nichols \& R. C. Schwartz (Orgs.), Terapia familiar: conceitos e métodos (pp.153-185). Porto Alegre: Artes Médicas.

Oliveira, D. S. (2005). Os comportamentos de dependência e de independência do primogênito e as percepções maternas no contexto de gestação do segundo filho. Dissertação de mestrado não-publicada, Universidade Federal do Rio Grande do Sul, Porto Alegre.

Pereira, C. R. R. (2006). Impressões e sentimentos maternos sobre o relacionamento mãe-primogênito durante a gestação do segundo filho. Dissertação de mestrado não-publicada, Universidade Federal do Rio Grande do Sul, Porto Alegre.

Piccinini, C. A., \& Alvarenga, P. (2000). Entrevista sobre praticas educativas parentais. Manuscrito não-publicado, Universidade Federal do Rio Grande do Sul, Porto Alegre.

Piccinini, C. A., Castro, E. K., Alvarenga, P., Vargas, S., \& Oliveira, V. Z. (2003). A doença crônica orgânica na infância e as práticas educativas maternas. Estudos de Psicologia (Natal), 8 (1), 75-83.

Piccinini, C. A., Frizzo, G. B., Alvarenga, P., Lopes, R. S., \& Tudge, J. (2007). Práticas educativas de pais e mães de crianças aos 18 meses de idade. Psicologia: Teoria e Pesquisa, 23 (4),369-378.

Piccinini, C. A., Lopes, R. C. S. Rossato, C., \& Oliveira, D. S. (2005). Estudo longitudinal sobre o impacto do nascimento do segundo filho na dinâmica familiar e no desenvolvimento emocional do primogênito. Manuscrito não-publicado, Universidade Federal do Rio Grande do Sul, Porto Alegre.

Polit, D. F., \& Falbo, T. (1987). Only children and personality development: a quantitative review. Journal of Marriage and the Family, 49 (2), 309-325.

Rivera, M., \& Carrasquillo, J. (1997). Spoiled or spectacular? A look at the only child. Information analyses. United States 
Department of Education. Office of Educational Research and Improvement. Educational Resources Information Center, 1-15.

Rosenberg, B. G., \& Hyde, J. S. (1993). Differential socialization of only and first-children. Paper presented at Society for Research in Child Development meetings, New Orleans, Louisiana.

Salvo, C. G., Silvares, E. F. M., \& Toni, P. M. (2005). Práticas educativas como forma de predição de problemas de comportamento e competência social. Estudos de Psicologia (Campinas), 22(2), 187-195. doi: 10.1590/S0103166X2005000200008.

Szymanski, H. (2004). Práticas educativas familiares: a família como foco de atenção psicoeducacional. Estudos de Psicologia (Campinas), 21 (2), 5-12. doi: 10.1590/S0103$166 \times 2004000200001$.
Tudge, J., \& Frizzo, G. B. (2002). Classificação baseada em Hollingshead do nível socioeconômico das famílias do Estudo Longitudinal de Porto Alegre: da gestação à escola. Manuscrito não-publicado, Universidade Federal do Rio Grande do Sul, Porto Alegre.

Tudge, J., Hayes, S., Doucet, F., Odero, D., Kulakova, N., Tammeveski, P., et al. (2000). Parents' participation in cultural practices with their preschoolers. Psicologia: Teoria e Pesquisa, 16 (1), 1-11.

Velásquez, A. M. Q. (1997). Cambios en la dinâmica familiar durante la gestación y el posparto. Investigación y Educación en Enfermería, 15 (1), 109-119.

Recebido em: 9/12/2008

Versão final reapresentada em: 12/4/2010

Aprovado em: 18/8/2010 